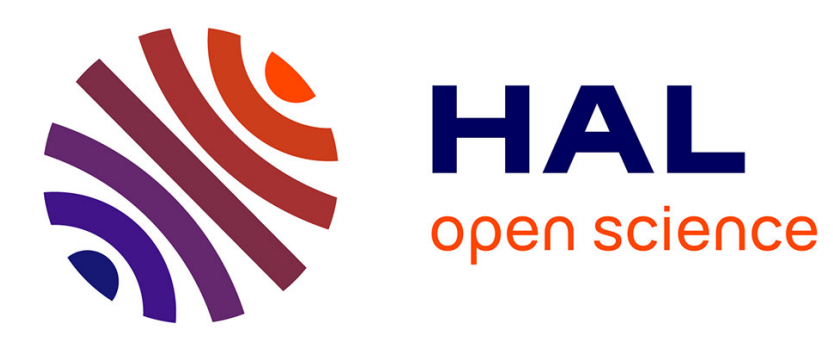

\title{
A Smart Assistant for Shooting Virtual Cinematography with Motion-Tracked Cameras
}

\author{
Christophe Lino, Marc Christie, Roberto Ranon, William Bares
}

\section{To cite this version:}

Christophe Lino, Marc Christie, Roberto Ranon, William Bares. A Smart Assistant for Shooting Virtual Cinematography with Motion-Tracked Cameras. ACM Multimedia, Nov 2011, Scottsdale, United States. hal-00646396

\section{HAL Id: hal-00646396 https://hal.inria.fr/hal-00646396}

Submitted on 19 Feb 2013

HAL is a multi-disciplinary open access archive for the deposit and dissemination of scientific research documents, whether they are published or not. The documents may come from teaching and research institutions in France or abroad, or from public or private research centers.
L'archive ouverte pluridisciplinaire HAL, est destinée au dépôt et à la diffusion de documents scientifiques de niveau recherche, publiés ou non, émanant des établissements d'enseignement et de recherche français ou étrangers, des laboratoires publics ou privés. 


\section{A Smart Assistant for Shooting Virtual Cinematography with Motion-Tracked Cameras}

\author{
Christophe Lino \\ IRISA/INRIA Rennes \\ Campus de Beaulieu \\ 35042, Rennes Cedex, France \\ christophe.lino@inria.fr \\ Roberto Ranon \\ $\mathrm{HCl}$ Lab, University of Udine \\ via delle Scienze 206 \\ 33100, Udine, Italy \\ roberto.ranon@uniud.it
}

\author{
Marc Christie \\ IRISA/INRIA Rennes \\ Campus de Beaulieu \\ 35042, Rennes Cedex, France \\ marc.christie@inria.fr \\ William Bares \\ Millsaps College \\ 1701 North State St Jackson \\ MS 39210 \\ bareswh@millsaps.edu
}

\begin{abstract}
This demonstration shows how an automated assistant encoded with knowledge of cinematography practice can offer suggested viewpoints to a filmmaker operating a hand-held motion-tracked virtual camera device. Our system, called Director's Lens, uses an intelligent cinematography engine to compute, at the request of the filmmaker, a set of suitable camera placements for starting a shot that represent semantically and cinematically distinct choices for visualizing the current narrative. Editing decisions and hand-held camera compositions made by the user in turn influence the system's suggestions for subsequent shots. The result is a novel virtual cinematography workflow that enhances the filmmaker's creative potential by enabling efficient exploration of a wide range of computer-suggested cinematographic possibilities.
\end{abstract}

\section{Categories and Subject Descriptors}

H.5.1 [Multimedia Information Systems]: Animations, Video

\section{Keywords}

Virtual Cinematography, Motion-Tracked Virtual Cameras, Virtual Camera Planning

\section{INTRODUCTION}

Creating camera edits and movements for computer generated animation remains time-consuming and largely manual endeavor requiring cinematographic skill and experience with 3D animation packages. Some technically-savvy filmmakers are now using motion-sensing devices to capture

Permission to make digital or hard copies of all or part of this work for personal or classroom use is granted without fee provided that copies are not made or distributed for profit or commercial advantage and that copies bear this notice and the full citation on the first page. To copy otherwise, to republish, to post on servers or to redistribute to lists, requires prior specific permission and/or a fee.

Copyright 20XX ACM X-XXXXX-XX-X/XX/XX ...\$10.00. complex virtual camera movements rather than key-framing the camera [1]. However, these existing devices operate as plugins to animation packages such as Maya that offer an infinity of expressive animation power, but with a corresponding steep learning curve and an interface which is not designed around cinematographic concepts.

Researchers in automated virtual cinematography systems have produced increasingly sophisticated algorithms that can generate virtual 3D camera work that mimics textbook guidelines $[4,2,3]$. But in succeeding to reduce human effort, these automated systems also limit the input of creative human filmmakers and as a result produce cinematography of little creative value. Our Director's Lens system introduces a novel workflow that combines the creative human intelligence with the computational power of an automated cinematography system, to enable a filmmaker to explore a variety of automatically suggested virtual camera compositions (see Figure 2), that represent a variety of cinematically distinct ways one might film a given shot and which are consistent in user-specified continuity properties with the previous shot. For computing its suggestions, the system exploits an annotated screenplay which provides the narrative context in the form of text descriptions of locations, subjects, and time-stamped actions, with links to the 3D models employed in the scene. Moreover, the system tries to mimic user's composition from previous shots.

With the help of a motion-tracked virtual camera (see Figure 1), the cinematographer can easily refine and use the suggestions as a starting point to craft his or her own cinematic compositions. Consequently, the expert is able to rapidly consider many more alternatives and the novice is guided towards options that conform to established cinema convention.

\section{NOVELTY AND BENEFITS}

This demonstration represents the very first coupling between motion-tracked camera devices - a fundamental technique in virtual cinematography - and automated viewpoint computation to support a filmmaker in his creative choices. The demonstration highlights both the creative potential the tool provides (movies can be made very rapidly) and the ease to play and explore the cinematic possibilities of a scenario. 


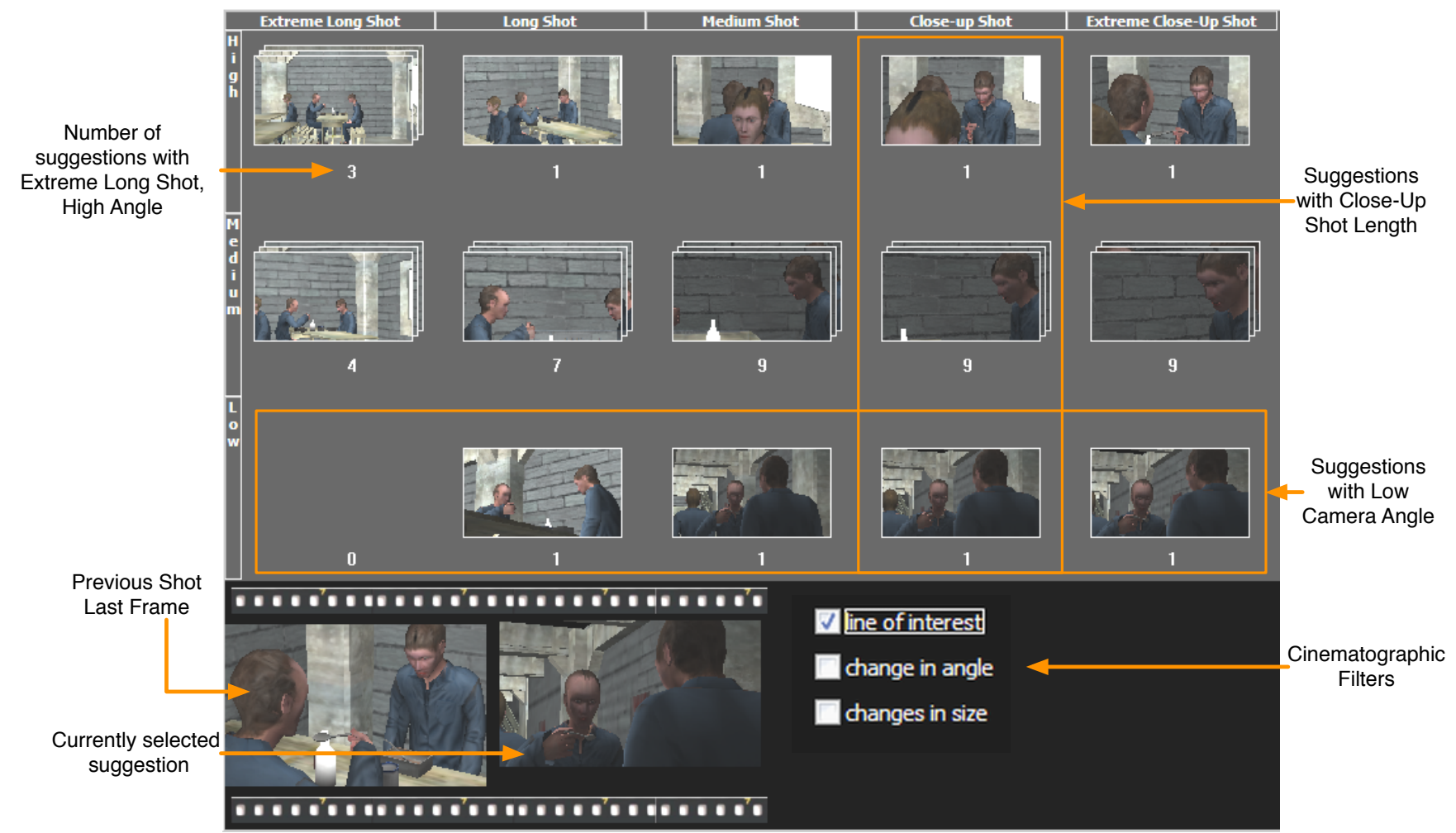

Figure 2: Screenshot of the interface in Explore Suggestions mode. The Line of Interest visual filter is selected, and thus only suggestions respecting the line of interest with respect to the previous shot last frame (pictured in the bottom left) are visualized.

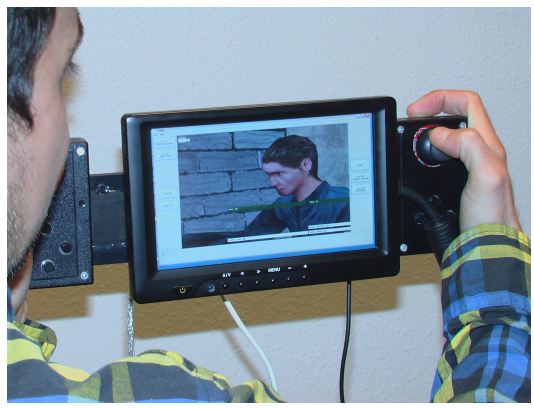

Figure 1: Our hand-held virtual camera device with custom-built dual handgrip rig and button controls, a 7-inch LCD touch-screen.

\section{DEMONSTRATION}

In this interactive demonstration of our Director's Lens system, a user operates a small hand-held touchscreen LCD screen equipped with motion sensors and custom-built button and joystick controls (see Figure 1) to record virtual camera movements (i.e., shots) to visualize a recreation of a scene from Michael Radford's film version of Orwell's 1984. The application runs on a notebook PC with a USB cable to communicate with the device's buttons, joysticks, and touchscreen, and an HDMI cable to mirror the PC's display on the handheld LCD. Three optical motion capture cameras mounted on tripods track the position and orientation of a rigid body marker cluster affixed to the device, which in turn map to the position and orientation of the virtual camera. We will also show a second version built from a Microsoft XBOX 360 gamepad and the same type of LCD touchscreen, but with a gyroscope sensor to drive camera orientation and the gamepad thumb sticks the camera's position.

A user can record a movie by iterating the following workflow: (i) identify the instant in the movie produced so far where a cut should be introduced (initially, at the beginning of the animation); (ii) ask the system to compute suggestion to start a new shot; (iii) browse the suggestions by cinematic properties (see Figure 2); (iv) choose the one that is closest to what the user likes; (v) possibly aim the virtual camera device to refine the composition, and start shooting, moving the the device like a real camera. An alternative, simpler workflow can very rapidly produce a sequence of static shots by simply exploring and selecting suggestions, without using the tracked device.

When browsing suggestions the user explore variations in shot distance, height, and angle in addition to whether or not suggestions conform to or differ from the previous shot in continuity, size, and angle. In this way the user can rapidly explore many different possible ways to film a given shot and assume manual control to improve upon the system's compositions and movements.

\section{REFERENCES}

[1] Autodesk. The new art of virtual moviemaking. Autodesk whitepaper, 2009. 
[2] D. Elson and M. Riedl. A lightweight intelligent virtual cinematography system for machinima generation. In 3rd Conference on AI for Interactive Entertainment (AIIDE), 2007.

[3] C. Lino, M. Christie, F. Lamarche, G. Schofield, and P. Olivier. A Real-time Cinematography System for Interactive 3D Environments. In $A C M$

SIGGRAPH/Eurographics Symposium on Computer Animation, pages 139-148. Eurographics Association, 2010.

[4] S. McDermott, J. Li, and W. H. Bares. Storyboard frame editing for cinematic composition. In $7 t h$ international conference on Intelligent user interfaces, pages 206-207. ACM Press, 2002. 